\title{
FINANCIAMENTO DA EDUCAÇÃO - LIMITES E AVANÇOS DO PLANO NACIONAL DE EDUCAÇÃO (2014-2024)
}

\author{
M. FRANÇA* \\ Universidade Federal do Rio Grande do Rio Grande de Norte - UFRN \\ magnaufrn@yahoo.com.br ${ }^{*}$
}

Artigo submetido em agosto/2016 e aceito em setembro/2016

DOI: $10.15628 /$ holos.2016.4999

\section{RESUMO}

O financiamento da educação tem respaldo na Constituição Federal de 1988, entre outras concernentes às fontes orçamentárias e de operação de crédito, principalmente, com os fundos contábeis. Dentre as várias legislações, citam-se: Emenda Constitucional no 14/96, que imprimiu nova forma de redistribuição de recursos da União para os estados e municípios criando o Fundef; LDB, Lei no 9.394/96; Emendas Constitucionais no $53 / 2006$ e no 59/2009, responsáveis pela criação do Fundeb e pela ampliação do ensino obrigatório (4-17 anos), respectivamente e a Lei n. 13005/2014 que aprovou o Plano Nacional de Educação (2014-2024). Integram o PNE eixos temáticos dentre eles o financiamento da educação, especificamente, a meta 20 que amplia a percentagem de aplicação do Produto Interno Bruto - PIB, para $10 \%$. O financiamento envolve os entes federados em regime de colaboração, e ação supletiva-redistributiva da União e dos Estados, estando, porém, condicionado à plena capacidade de atendimento e esforço fiscal dos entes federativos. O resultado da análise dos dados mostra que os recursos existentes são escassos para o fortalecimento da gestão e financiamento do PNE, sendo apresentados desafios para angariar novas fontes de recursos, bem como implementar a Lei $12.858 / 2013$ que destina $75 \%$ dos royalties do petróleo e $50 \%$ do Fundo Social do Pré-Sal para a educação.

PALAVRAS-CHAVE: Financiamento da educação, Fontes de recursos, PNE (2014-2024).

\section{EDUCATION FINANCING - LIMITS AND ADVANCES OF NATIONAL PLAN FOR EDUCATION (2014-2024)}

\begin{abstract}
Education financing is based on Constituição Federal (1988), among other documents concerned to budget resources and credit operation, mainly to the accounting assets. Among many laws, there are: Constitutional Amendment n. 14/96 that creates a new form of redistribution of resources from Union to the States and cities with Fundef; LDB, Law n. 9.394/96; Constitutional Amendment n. 53/2006 and n. 59/2009 which creates Fundeb and improves compulsory education (4-17 years), respectively; and Law n. 13005/2014 that approve Education National Plan - PNE (2014-2024). Some thematic axes integrate PNE, as education financing,
\end{abstract}

specifically aim 20 that widen to 10 the percentage of Gross Domestic Product (GDP) application. Financing involves political units in collaboration system and redistributive and supplementary action from Union and States. However, this is conditioned by capacity of attending and fiscal efforts from political units. The result of data analyze shows the resources are scarce to reinforce manager and PNE financing, presenting some challenges to gain new source of resources, as well as, to implement Law $12.858 / 2013$ that send $75 \%$ of oil royalties and $50 \%$ of Social Asset from Pre-Salt to education.

KEYWORDS: Education financing, Source of resources, PNE (2014-2024). 


\section{INTRODUÇÃO}

O financiamento da educação pública brasileira se situa no centro dos problemas e desafios que se apresentam no Brasil. A educação é um dever do Estado, e a forma adotada no Brasil é a federativa. A educação deve configurar uma unidade, tanto social como política dentro de seus limites, possibilidades e recursos existentes, em todo Plano de Estado. Na questão social, o interesse demanda em realizar as promessas e os valores a ela contemplados. Na política, justificase pelo fato de, nos países federativos, ocorrer um equilíbrio entre unidade nacional e diversidade regional. Nesse sentido, a obrigação, quanto ao financiamento do Estado para a educação pública em todos os níveis e modalidades do ensino, fundamenta-se no fato de que a educação constitui um direito social, universal, consequentemente, dever do Estado.

Visando garantir um direito social no sentido de contestar o mercado como bem absoluto, propiciando realizações educacionais adotadas pelos entes federativos, no ordenamento jurídico representado pelas Constituições Federais de 1934, 1961 e 1988, bem como na LDB, Lei no 9.394/96, consagrou-se a ideia de um Plano Nacional de Educação - PNE (CURY, 2013).

No Brasil, essa prática tende a se repetir a cada dez anos, quando planos, especificamente, os dois últimos tiveram respaldo legal, ou seja, o PNE de 2001-2010 pela Lei №. 10.172/2001e o novo Plano para o período (2014-2024), aprovado pela Lei no. 13.005/2014.

Dourado (2014) esclarece que o novo PNE tem metas de garantir a universalização da educação básica até 2016, ou seja, o acesso e aprovação com qualidade, cuja implementação desmandará mudanças estruturais, sobretudo porque a desigualdade educacional se articula à desigualdade social e exige atenção para a concentração de riquezas, o que implica em uma reforma tributária.

O PNE foi um avanço envolvendo a mobilização das sociedades civil, política e do campo educacional, cujas questões centrais constam no Documento-Referência da Conferência Nacional de Educação - CONAE 2014. Esse Documento-referência suscitou o movimento de discussão referente às diretrizes do novo PNE para a educação básica e superior, trazendo o debate político e social sobre o sistema nacional de educação, assegurando a articulação entre os entes federados e os setores da sociedade civil, cujos eixos temáticos têm como perspectivas: democratização, universalização, qualidade, inclusão, igualdade, diversidade, valorização dos profissionais da educação e o financiamento da educação, constituindo-se em um marco histórico para a educação brasileira na contemporaneidade.

O PNE exige a vinculação de recursos, assim como, a ampliação da percentagem de aplicação do Produto Interno Bruto - PIB, para 10\%, impondo, como medida racional, a sua maximização em função de sua aplicação final, ou seja, a universalização e a qualidade do ensino, no caso específico, para a educação básica.

Com as oscilações entre mercado e o Estado mediadas pelas forças sociais presentes na sociedade e com as promessas de maior investimento pela União visando minimizar as desigualdades sociais, o novo PNE se articula num movimento de interação visando ao sistema nacional de educação via regime de colaboração. $E$, como ampliação do direito subjetivo de todo cidadão à educação propõe, na prática, políticas de colaboração e de cooperação entre os entes federados para ampliação do financiamento e outras fontes de recursos financeiros. 
As manifestações foram importantes na tentativa de alcançar os $10 \%$ do PIB, citados na Meta 20, mas ainda insuficientes para garantir a destinação do total dos novos recursos à educação pública.

Os aspectos jurídicos para o financiamento têm respaldo na Constituição Federal de 1988, dentre outras, concernentes às fontes orçamentárias e de operação de crédito, principalmente, com a política de Fundos contábeis. Dentre as várias legislações, citam-se as mais relevantes: Emenda Constitucional $\mathrm{n}$ - 14/96, que imprimiu nova forma de redistribuição de recursos da União para os estados e municípios; a LDB, Lei no 9.394/96; a Lei no 9.424/94 normatizando o Fundo de Manutenção e Desenvolvimento do Ensino Fundamental e Valorização do Magistério (Fundef); as Emendas Constitucionais no 53/2006 e no 59/2009, responsáveis pela criação do Fundo de Desenvolvimento da Educação Básica e Valorização dos Profissionais da Educação - Fundeb e pela ampliação do ensino obrigatório da pré-escola ao ensino médio (4 a 17 anos, até 2016), respectivamente.

O Fundeb é considerado pela política governamental o primeiro regime cooperativo consolidado em âmbito de toda a educação básica. O segundo é o Piso Salarial Profissional Nacional do Magistério - PSPN, tendo, como respaldo, a Lei no. 11.738/2008, que, por sua vez, é originária da Lei do Fundeb.

Ressalva-se que a EC no 59/2009, além da exigência da ampliação da faixa etária escolarizável (estratégia essa constatada no novo PNE), deixa explícito o comprometimento da União com a universalização da educação básica, determinando, também, a redução, anualmente, do percentual da Desvinculação das Receitas da União (DRU), sendo esses recursos descentralizados para os estados e municípios, como forma de complementação, em face da manutenção daquele nível de ensino.

O Fundeb cujos recursos estão sujeitos à redistribuição em função das matrículas constitui um forte fator de indução ao regime de colaboração, sendo este o principal financiador da educação básica. "É preciso, pois, buscar o equilíbrio federativo, por meio da prática de solidariedade federativa, da preservação da igualdade de autonomias e da dosagem de recursos distribuídos em face dos encargos atribuídos" (MARTINS, 2013).

É nesse contexto que se converge a análise deste trabalho, buscando apresentar reflexões relacionadas às proposições de regime de colaboração e cooperação, fontes e recursos de financiamento da educação básica e política dos Fundos, convergindo para os limites e avanços quanto a financiamento das metas do Plano Nacional de Educação (2014-2024).

\section{FONTES, RECURSOS E O REGIME DE COOPERAÇÃO}

Pertinente à política de financiamento para a educação básica, prevalece a transferência de recursos e de encargos da União para os municípios. Assim, vários mecanismos foram instituídos, entre eles: a Lei de Ensino no. 5.692, de 11.09.1971, art. 59, em que a transferência de encargos tem, como ponto de partida, a Reforma de Ensino de 10 e 20 graus, a qual inscreveu a descentralização administrativa da educação como estratégia política. Em seguida, a Constituição Federal de 1988 e, logo após, vários dispositivos legais, dentre eles, a LDB, Lei no 9.394/96.

A redefinição do papel do Estado, a partir da Constituição de 1988, impôs competências e atribuições a União, Estados e Municípios. Esse aparato institucional imprime, particularmente, ao 
Município brasileiro, uma nova configuração, conclamando-o a estruturar seu próprio sistema de ensino e a participar do regime da responsabilidade compartilhada - sistema político de colaboração, Constituição Federal de 1988. Essa Constituição garantiu que a União deveria aplicar $18 \%$ de sua receita líquida de impostos em educação, cabendo aos Estados, Distrito Federal e Municípios a aplicação de $25 \%$ da mesma base. Outra fonte de recursos é definida como Salárioeducação - uma contribuição social paga pelas empresas - que financia, também, a educação básica.

No entendimento sobre o financiamento da educação pública, Abrahão (2005) esclarece que, segundo as normas legais vigentes, deve ser efetivada pela União, pelos Estados, pelo Distrito Federal e pelos Municípios, que têm a responsabilidade e competência pela manutenção e expansão do sistema de ensino.

A União deve aplicar recursos na implementação de alguns programas, que caracterizam ações próprias, além de transferir recursos para os sistemas estaduais e municipais. Na composição de suas receitas, os estados somam os recursos recebidos da União aos provenientes de suas fontes, os quais são utilizados na manutenção e expansão de seus sistemas de ensino. Na composição dos recursos destinados à manutenção e à expansão de suas redes de ensino, os municípios recebem recursos da União e dos Estados, os quais são somados aos seus recursos próprios.

Para resguardar o direito à educação, o Estado estabeleceu a estrutura e as fontes de financiamento, ao determinar, em legislação, a vinculação de recursos financeiros para a educação, contidas nas legislações citadas e em demais leis ordinárias.

Nesse contexto, a atual política de financiamento está imbricada nas relações federativas entre União, Estados, Distrito Federal e Municípios. Farenzena e Araújo (2005) argumentam que o financiamento constitui uma espécie de linha de fronteira que demarca as possibilidades de atuação dos entes federados e a amplitude de suas opções e estratégias na consecução de políticas próprias ou de políticas de colaboração intergovernamental.

Rossinholi (2010), ao analisar a Constituição Federal de 1988 (BRASIL, 1988, art. 2011), entre outros elementos, diz que ela se caracterizou pela descentralização financeira, representando um aumento da participação de estados e principalmente de municípios na arrecadação tributária e na receita disponível, passando a ter a função redistributiva e supletiva, visando garantir a equalização de oportunidades educacionais. Entretanto, cada esfera administrativa possui atuação prioritária com as modalidades do ensino.

Os recursos vinculados constitucionalmente à Manutenção e ao Desenvolvimento do Ensino (MDE) se originam de uma fatia da receita pública, de créditos operacionais e contribuições sociais. Os recursos públicos são, na maioria, originários da receita de treze impostos conforme demonstra Dourado (2006), sendo o Imposto sobre Circulação de Mercadorias (ICMS) aquele que arrecada mais recursos direto para o Fundeb.

As receitas provenientes de transferências que tenham como origem os impostos devem ser computados como se fossem impostos, para efeitos de vinculação. Assim, os estados e o Distrito Federal devem adicionar à sua receita de impostos, transferências oriundas da União que tenham como base os impostos. De igual modo, os municípios devem proceder, incorporando à sua base de cálculo para MDE as transferências do estado e da União que tenham como origem os 
mesmos impostos. Consideram-se, pois, as alíquotas referentes à União (18\%) e aos estados, Distrito Federal e municípios (25\%) que devem incidir sobre a receita líquida dos impostos.

As transferências de recursos são realizadas de uma esfera da administração para outra, tendo como finalidade equalizar a capacidade arrecadadora e as responsabilidades na prestação de serviços das diferentes esferas da Administração Pública. Os fundos de participação dos estados e dos municípios são exemplos dessas transferências de recursos.

Além dos impostos próprios da União, dos estados, do Distrito Federal e dos municípios, ou seja, tributo arrecadado diretamente por cada ente federado, existem outras fontes de captação de recursos para a educação, provenientes de receita de transferências constitucionais e outras transferências; contribuição do Salário-educação, outras contribuições sociais; receita de incentivos fiscais e outros recursos previstos em lei.

Conforme Duarte (2005), o sistema de educação básica no Brasil pode ser caracterizado, em linhas gerais, como um sistema público federativo que tem por suporte o financiamento fiscal proveniente de fontes de receitas estaduais e municipais.

A estrutura de financiamento é complexa, com a ampliação dos recursos dependente do crescimento da arrecadação proveniente de fontes do aparato fiscal específico e desigual dos estados e municípios, com expressiva participação das transferências constitucionais obrigatórias. Uma parcela expressiva provém de contribuição social já citada anteriormente, o Salário-educação. De acordo com Castro e Sadeck (2003), representa aproximadamente 5,6\% do total das receitas vinculadas. Outra parte provém de operações de crédito com agências internacionais e, por último, há fontes em que entram desde as aplicações financeiras do Fundo Nacional de Desenvolvimento da Educação (FNDE) até os recursos arrecadados diretamente pelos sistemas de ensino (estaduais e municipais) e pelas instituições vinculadas ao setor privado.

No Brasil, estudos sobre federalismo e direito à educação, na concepção de Cury, (2002) apontam para a necessidade de aprofundar as análises sobre o modo de regulação das relações intergovernamentais. Embora a previsão constitucional de lei complementar fixando normas para a cooperação não tenha sido cumprida, o autor afirma que considera as reformas no financiamento da educação básica, empreendidas a partir da EC no. 14/1996, articulando meios e competências desiguais.

Orientados pela norma legal, o regime de financiamento envolvendo os entes federados deve se pautar pela colaboração, pela ação supletiva e distributiva da União e dos Estados, estando, porém, condicionada à plena capacidade de atendimento ao esforço fiscal de Estados, do Distrito Federal e dos Municípios.

\section{POLÍTICA DOS FUNDOS}

A descentralização financeira dos recursos decorre da regulação política do sistema de financiamento da Educação Básica. Segundo Duarte (2005), tem, como objetivo, a obtenção de ganhos de eficácia e eficiência, no sentido de compatibilizar a expansão do atendimento com restrição orçamentária. Nessa política de financiamento, a autonomia política dos sistemas locais de ensino e das unidades escolares encontra-se circunscrita pelas dimensões da criação de Fundos e programas destinados à efetiva organização e ao funcionamento do sistema educacional como um todo. 
A proposição da política de Fundos está circunscrita à política de descentralização que vem sendo delineada para a educação básica a partir da reforma educacional dos anos de 1990.

O eixo norteador dessa política está voltado para o acesso e permanência de estudantes à educação básica, aliado a uma educação de qualidade, bem como à valorização dos profissionais da educação.

Ressalva-se ser imprescindível a otimização de recursos, visto que significa criar condições para uma maior eficiência e, em consequência, mais agilidade e transparência na prestação de serviços públicos pelo Estado, presumindo, ainda, um efetivo envolvimento direto do poder local na captação de recursos, no controle de gastos e na inspeção do cumprimento das metas estabelecidas.

Nesse contexto, a reforma da educação proporcionou reformulações em bases legais, começando pela alteração da legislação no que concerne ao financiamento da educação, com base na Emenda Constitucional no 14/96 (BRASIL, 1996) que cria o Fundef, antes constituído da subvinculação do orçamento da educação advinda dos Estados, Municípios e Distrito Federal, ficando a União encarregada de complementar, apenas, os Estados onde o Fundo não foi suficiente. O Fundef - enquanto mecanismo de financiamento do Ensino Fundamental - alterou os artigos 34, 208, 211 e 60 da Constituição Federal de 1988 (BRASIL, 1988), tendo sua regulamentação ocorrida pela Lei no 9.424/96 (BRASIL, 1996). A posteriori, é substituída pela Emenda Constitucional no 53/06 e pela Lei no 11.494/07 que regulamentam o Fundeb.

O Fundeb conservou os mesmos mecanismos de captura e de redistribuição de recursos instaurados pelo Fundo anterior. No entanto, ampliou significativamente a abrangência de financiamento a todas as etapas e modalidades da educação básica, contando, para isso, com um maior aporte de recursos decorrente da elevação do percentual subvinculado de um número maior de impostos (BRASIL, 2007).

O referido Fundo tem vigência de 14 anos, ou seja, de 2006-2020, sendo sua implantação gradativa com o crescimento dos percentuais dos impostos que já compunham o Fundef para $16,66 \%, 18,33 \%$, e $20 \%$, no primeiro, segundo e terceiro ano, respectivamente, ou seja, 2007 a 2009. Para os novos impostos incluídos, o percentual foi de $6,66 \%, 13,33 \%$ e $20 \%$, respectivamente. A lei estabelece que a porcentagem dos recursos para a formação do Fundo será alcançada, paulatinamente, nos primeiros 3 (três) anos de vigência dos Fundos (BRASIL, 2007). A partir de 2009, atenderia, integralmente, a toda a educação básica.

Compõem o Fundeb os impostos que já faziam parte da cesta do Fundef: o FPE, FPM, ICMS, IPI-Exp e os recursos advindos da Lei Complementar no 87/96, sendo acrescidos dos demais: ITCMD, IPVA e ITR.

Vale destacar que o Fundeb, além de ter como função principal a universalização da educação básica, trouxe avanço e conquista quanto à valorização do magistério, ao proporcionar o Piso Salarial Profissional Nacional, aprovado pela Lei no 11.738/08, estabelecendo o teto mínimo para o professor, somente com magistério (nível médio) e normatizando a carga horária para atividades extraclasses. 


\title{
4 O FINANCIAMENTO E ESTRATÉGIAS NO CONTEXTO DO PLANO NACIONAL DE EDUCAÇÃO (2014-2024)
}

A luta pela vinculação de verbas públicas exclusivamente para a educação pública constitui objeto de mobilizações da sociedade e está presente em todos os movimentos desde a década de 1930, ocorrendo, também, o embate de recursos entre educação pública versus educação privada, fato esse acontecido no novo PNE, em face da exclusividade de verbas públicas para a educação pública.

Saviani (2014), ao reportar sobre verbas públicas, afirma ser necessária a organização dos educadores num grande movimento em defesa da escola pública para libertá-la da subordinação ao mercado e da pressão dos interesses privados, sendo esse movimento histórico pela destinação de verbas públicas exclusivamente para a educação pública, desejando que essas manifestações sejam lutas vitoriosas.

Dourado (2014) alerta que, com o texto aprovado (PNE), não foi diferente, e a exclusividade citada não logrou êxito. O referido autor chama a atenção junto à meta progressiva de investimento na educação (ampliação do percentual do PIB), trazendo o conceito de público para a:

\begin{abstract}
Inclusão dos recursos direcionados aos programas de expansão profissional e superior, inclusive na forma de incentivo - isenção fiscal, bolsas de estudos concedidas no Brasil e no exterior, além dos subsídios a programas de financiamento estudantil, financiamento de creche pré-escolas e educação especial, na forma do art. 213 da Constituição Federal (DOURADO, 2014, p. 234).
\end{abstract}

Ademais, o autor argumenta que o Plano tem desafios e deve tornar-se um Plano de Estado e que a sua efetivação deve intermediar o debate entre sociedade civil e sociedade política, não esquecendo a disputa do setor privado, inclusive o financeiro, pelos fundos públicos. Mobilizações devem acontecer para garantir a expansão pública, como por exemplo, "a educação básica, predominantemente pública com a expectativa de que assim continue, a educação superior, com a previsão de 40\% de novas matriculas no segmento público" (DOURADO, 2014, p. 234).

Visando ao fortalecimento de sua gestão e financiamento, desafios são postos para o PNE para atender à quantidade expressiva de jovens e adolescentes que ainda não têm acesso à escola básica.

Conforme dados do IBGE/PNAD (2009) e Unicef (2012), o Brasil apresenta um total de 3.690.569 de jovens e adolescentes que não têm acesso à escola, sendo que, desse montante, a maioria da parcela está na faixa etária de 15 a 17 anos, idade essa equivalente ao ensino médio. Em segundo plano, observa-se a população de menor idade, ou seja, as crianças da educação infantil de 4 a 5 anos. A população intermediária tem correlação com a idade dos alunos do ensino fundamental (7 a 14 anos), o que comprova que ela se encontrava em sala de aula, no final da década de 2000, ou seja, os 97\%, conforme informações do Inep/MEC.

Observa-se, pois, que, apesar de o Brasil estar numa posição privilegiada quanto à universalização do ensino fundamental, as taxas de frequência líquida mostram que o país ainda está longe da universalização em relação às crianças de até 5 anos e os adolescentes de 15 a 17 anos, ou seja, na educação infantil e no ensino médio, respectivamente. Eles representam, hoje, o maior contingente fora da escola. 
Outras informações sobre as regiões e estados deixam claro que, no Rio Grande do Sul, (Região Sul) 98,8\% das crianças e dos adolescentes de 7 a 14 anos estão na escola. Nas regiões Norte e Nordeste, os estados do Pará, Rio Grande do Norte, Amazonas e Alagoas, os números representam percentuais em torno de $96,7 \%, 96,7 \%, 96,5 \%$ e $95,2 \%$, respectivamente, sendo, pois, os mais baixos do país.

Informações do Inep/MEC (2012) mostram a evolução da aplicação do PIB nacional no gasto em educação: em 2000, foram aplicados 3,90\%; em 2006, subiu para 4,30\%; em 2011, foi a 5,30\%, encerrando-se 2012 com 5,50\%. Quando se analisa o ensino por modalidade - fundamental, médio e superior - verifica-se que a União tem acrescido sua participação em todos os períodos citados, mantendo um equilíbrio proporcional. Análise preliminar aponta que, com os recursos, hoje, existentes, mesmo considerando a projeção, o investimento em Educação, para os próximos 10 anos, não será suficiente para se alcançar o patamar de $10 \%$, preconizada na Meta 20 do PNE (2014-2024), tornando-se viável novas fontes de recursos.

Mediante esse cenário, é preciso questionar e defender mais recursos para a educação, de forma descentralizada, a exemplo dos Fundos. Os Fundos e a relação com as fontes de recursos, a estrutura de financiamento da educação são fortemente baseados em impostos, que são recursos gerais tomados à sociedade. Isso significa que uma parcela expressiva dos recursos, principalmente de estados, Distrito Federal e municípios, é proveniente da arrecadação tributária, sobretudo, em razão da vinculação de impostos.

O PNE deve sustentar, politicamente, a proposta de uma educação básica de qualidade, com responsabilidade comum aos entes federativos, referendado pela Meta 20, indicando um percentual de $10 \%$ do PIB até o final de sua vigência, devido: a) a um Sistema Nacional Articulado de Educação; b) ao financiamento à educação que deve tomar como referência o CAQ em face dos custos dos alunos; c) à ampliação dos gastos públicos com educação de 5.2\% em 2012, para 10\% do PIB até o final de sua vigência; d) à complementação da União para o Fundeb aos estados e municípios alcance o patamar de 1\% do PIB; e) à implementação da Lei no 12.858/2013 que destina $75 \%$ dos royalties do petróleo e $50 \%$ do Fundo Social do Pré-Sal para a educação e, d) à criação da lei de Responsabilidade Educacional ${ }^{1}$. Essas percentagens de recursos e procedimentos são fundamentais para o cumprimento das metas do Plano Nacional de Educação (2014-2024). Complementando, considerando a necessidade de universalização da educação básica, os gastos e os limites que as unidades federativas têm com a educação, Dourado (2014, p. 245) esclarece sobre a "necessidade de rediscutirmos a Lei de Responsabilidade Fiscal dentro de uma perspectiva de reforma tributária, em uma perspectiva mais ampla e se não avançarmos em face ao Fundeb vai ser muito difícil cumprir as metas do Plano".

As proposições adotadas constituem-se em estratégias para a implementação de políticas de Estado para a educação nacional, em consonância com as lutas históricas e debates

\footnotetext{
${ }^{1}$ A educação tem uma dinâmica própria que não se coaduna com o espirito e a letra da Lei de Responsabilidade Fiscal (LRF), pois, os gastos com pessoal têm, compreensivelmente, um peso maior, não podendo se enquadrar no milite máximo dos $60 \%$. É preciso encarar com cuidado o enunciado da estratégia 20.11 do PNE que determina a aprovação, no prazo de um ano, da Lei de Responsabilidade Educacional (LRE). \{...\}A ideia que tende a prevalecer é tomar a LRF como referência para a elaboração da LRE, o que, aliás, corresponde às pressões do mercado com as quais estão alinhadas as entidades privadas no campo da educação e que vêm exercendo uma influência cada vez maior na formulação e execução da política educacional, tendo em vista o Movimento "Todos pela Educação" (SAVIANI, 2014, p. 245-6).
} 
democráticos construídos pela sociedade ${ }^{2}$, movimentos sociais e pelo governo, na garantia da educação como bem público e direito social, resultando, assim, na participação e na cooperação federativa com regime de colaboração.

Notas

\section{REFLEXÕES FINAIS}

O financiamento da educação pública brasileira se situa no centro dos problemas e desafios que se apresentam no Brasil em face da implementação de políticas públicas. A educação é um dever do Estado, e a forma adotada no Brasil é a federativa. Nesse sentido, a obrigação, quanto ao financiamento do Estado para a educação pública, em todos os níveis e modalidades do ensino, fundamenta-se no fato de que a educação constitui um direito social, universal, portanto, dever do Estado.

"Algumas iniciativas podem se constituir em elementos mobilizadores, no sentido de edificar mecanismos mais claros e pactuados entre os entes federados para a definição e implementação de políticas públicas" (CABRAL NETO, 2014, p. 5), sendo, no nosso entendimento, contemporizadas pela legislação citada e, no atual contexto, com o Plano Nacional de Educação.

O PNE constitui-se em uma ferramenta política e institucional para superar, com recursos e investimentos, obstáculos visando promover a qualidade e a quantidade da oferta de um serviço público estratégico para o projeto republicano da nação brasileira, pela via do regime de colaboração entre os entes federativos, com recursos públicos para uma educação pública.

$\mathrm{O}$ alcance das metas contidas no PNE, bem como em planos estaduais e municipais, depende de políticas, legislação, investimentos e gestão de recursos adequados.

A discussão de mais investimentos na educação passa por um debate, também, sobre o condicionamento da Lei de Responsabilidade Fiscal quando determina o mínimo de $60 \%$ de gastos com pessoal. Várias estratégias do PNE dependem de mais recursos humanos qualificados e piso salarial condizente ao educador. Na concepção de Araújo Filho (2014), enfrentam-se muitas dificuldades com o limite imposto pela LRF sobre a folha salarial. Ocorre a redução do quadro de pessoal efetivo nos estados e municípios, aumento de contratações temporárias com salários menores, redução dos percentuais na carreira profissional dos professores (licenciatura e pósgraduação), em função dos limites dessa Lei e do controle pelos tribunais de contas dos estados. O autor argumenta que a Confederação Nacional dos Trabalhadores em Educação defende a retirada da educação dos limites impostos pela LRF, em face do atendimento às demandas e à melhoria do piso salarial e da infraestrutura das escolas.

A mobilização política da sociedade civil, a regulamentação legal pelo poder legislativo dos aspectos demandados pelo PNE - instância de cooperação federativa, lei de responsabilidade educacional e vinculação de recursos da exploração de recursos naturais - e a atuação administrativa e financeira dos gestores governamentais, inerentes às premissas e metas do Plano

\footnotetext{
${ }^{2}$ A Confederação Nacional dos Trabalhadores em Educação (CNTE) - compreende que a qualidade da educação se apoia nos eixos financiamento, valorização profissional, gestão democrática e avaliação institucional, reafirmando a perspectiva de que o PNE deva focar políticas públicas para atender a esses requisitos, para a educação básica, em cada região do País (BRASIL, 2013).
} 
Nacional de Educação, imprimem novo alento à superação dos desafios históricos da educação no Brasil (universalidade, gratuidade e qualidade). Resta o desafio para que os atores elencados assumam seus papéis e efetivem suas atribuições, principalmente o investimento em educação de acordo com a meta 20 do PNE. Esses interlocutores, segundo Dourado (2014), devem contribuir de maneira propositiva para transformar, de fato, o PNE em um Plano que assuma o epicentro das políticas educativas, traduzindo aquilo que tanto anseia a sociedade - mais oportunidades educacionais e mais qualidade.

O investimento de recursos públicos constitui um dos pontos principais para se obter uma educação pública de qualidade, considerada um direito de todos.

\section{REFERÊNCIAS BIBLIOGRÁFICAS}

1. ABRAHÃO, Jorge. Financiamento e gasto público da educação básica no Brasil e comparações com alguns países da OCDE e América Latina. In: Políticas públicas de regulação: problemas e perspectivas da educação básica. Educação e Sociedade. Revista de Ciências da Educação. São Paulo: Cortez, CEDES. Vol. 26, N. Especial 92, 2005.

2. ARAÚJO FILHO, Heleno. PNE 2014-2024: desafios para a educação brasileira. Entrevista. Revista Retratos da Escola. CNTE. Brasília, vol. 8, n. 15, jul/dez/2014.

3. BRASIL. Constituição da República Federativa do Brasil: texto constitucional promulgado em 1988, com alterações adotadas pelas Emendas Constitucionais. Brasília: Senado Federal, Subsecretaria de Edições Técnicas, 2008.

4. BRASIL. Constituição (1988). Emenda Constitucional no 53, de 19 de dezembro de 2006. Dá nova redação aos artigos 7ํ, 23, 30, 206, 208, 211 e 212 da Constituição Federal e ao art. 60 do Ato das Disposições Constitucionais Transitórias, 2006a. Disponível em: <http://www.planalto.gov.br/ccivil_03/constituicao/emendas/emc/emc53.htm>. Acesso em: 23 maio 2011.

5. BRASIL. Lei no 11.494, de 20 de junho de 2007. Regulamenta o Fundo de Manutenção e Desenvolvimento da Educação Básica e de Valorização dos Profissionais da Educação FUNDEB, de que trata o art. 60 do Ato das Disposições Constitucionais Transitórias; altera a Lei $\mathrm{n}$ - 10.195 , de 14 de fevereiro de 2001; revoga dispositivos das Leis $\mathrm{n}$ os 9.424 , de 24 de dezembro de 1996, 10.880, de 9 de junho de 2004, e 10.845, de 5 de março de 2004; e dá outras providências. Disponível em: <http://www.fnde.gov.br/index.php/fundeb-legislacao>. Acesso em: 23 maio 2011.

6. BRASIL. Lei $\mathbf{n}$ - 11. 738, de $\mathbf{1 6}$ de Julho de 2008. Regulamenta a alínea "e" do inciso III do caput do art. 60 do Ato das Disposições Constitucionais Transitórias, que institui o piso salarial profissional nacional para os profissionais do magistério público da educação básica. Disponível em: <http://www.diariodasleis.com.br/busca/exibelink.php?numlink=1-98-24-2008-07-1611738> Acesso em: 23 maio 2011.

7. CABRAL NETO. Plano Nacional e Sistema Nacional de Educação: a difícil tarefa de conceber uma política de Estado. In: FRANÇA, Magna; MOMO Mariângela (Orgs.). Processo Democrático Participativo: a construção do PNE. Campinas: SP, Mercado de Letras, 2014.

8. CASTRO, Jorge Abrahão de; SADECK, Francisco. Financiamento do gasto em Educação das três 
esferas de governo em 2000. Brasília: Ipea, jun. 2003. (Texto para Discussão, n. 955).

9. CURY, Carlos Roberto Jamil. Federalismo político e educacional. In: FERREIRA, N. S. C (Org.). Políticas públicas e gestão da educação: polêmicas, fundamentos e análises. Brasília: Líber Livro Editora, 2006.

10. CURY, Carlos Roberto Jamil. Planos Nacionais de Educação no Brasil. In: FERREIRA, Eliza Bartolozzi; FONSECA; Marília (Orgs.). Política e Planejamento Educacional no Brasil do século 21. Brasília: DF, Liber Livro, 2013.

11. DOURADO, Luís Fernandes. Financiamento da educação no Brasil: aportes teóricos e a construção de uma rede de pesquisadores. In: GOUVEIA, A.B.; SOUZA, A.R.; TAVARES, T.M. (Org.). Conversas sobre financiamento da educação no Brasil. Curitiba: UFPR, 2006. p. 27-40.

12. DOURADO, Luís Fernandes. PNE 2014-2024: desafios para a educação brasileira. Entrevista. Revista Retratos da Escola. CNTE. Brasília, vol. 8, n. 15, jul/dez/2014.

13. DUARTE, Marisa Ribeiro Teixeira. Regulação Sistêmica e a Política de Financiamento da Educação Básica. Educação e Sociedade, São Paulo, v. 26, 2005. N. Especial.

14. FARENZENA, Nalú. Diretrizes da política de financiamento da educação básica: continuidade e inflexões no ordenamento constitucional-legal (1987-1996). Porto Alegre: FACED: UFRGS, 2001.

15. FARENZENA, Nalú; ARAUJO, Emílio. Espaços de democratização na gestão financeira da educação. Porto Alegre: FACED: UFRGS, 2005.

16. MARTINS, Paulo de Sena. Política e Planejamento Educacional no Brasil do século 21. In: FERREIRA, Eliza Bartolozzi; FONSECA, Marília. (Orgs.). Política e Planejamento Educacional no Brasil do século 21. Brasília: DF, Liber Livro, 2013.

17. ROSSINHOLI, Romualdo P. de \& ADRIÃO, Thereza. Gestão, financiamento e direito à educação: análise da LDB e da Constituição Federal. São Paulo: Xamã, 2001.

18. SAVIANI, Dermeval. PNE 2014-2024: desafios para a educação brasileira. Entrevista. Revista Retratos da Escola. CNTE. Brasília, vol. 8, n. 15, jul/dez/2014. 